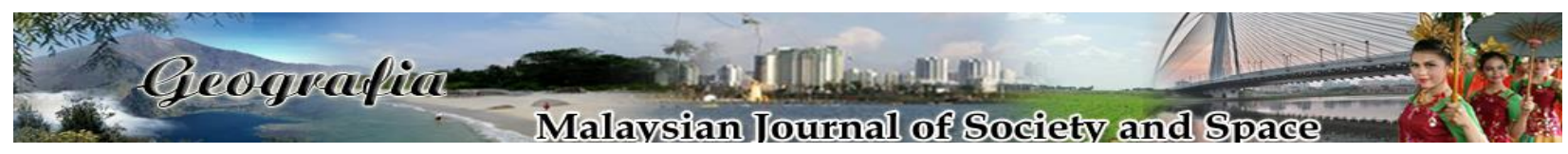

\title{
Faktor PSiKKIT: Pendorong inovasi pembungkusan dalam kalangan Industri Kecil dan Sederhana berasaskan perusahaan makanan
}

\author{
Mahani Amat, Suraiya Ishak \\ Program Sains Pembangunan, Pusat Pembangunan, Sosial dan Persekitaran, \\ Fakulti Sains Sosial dan Kemanusiaan, Universiti Kebangsaan Malaysia \\ Correspondence: Mahani Amat (email: mahanihalimi@gmail.com)
}

Received: 01 February 2019; Accepted: 30 April 2019; Published: 22 August 2019

\begin{abstract}
Abstrak
Pembungkusan produk makanan memainkan peranan penting untuk menarik pengguna. Terdapat banyak produk berkualiti yang telah dihasilkan usahawan Industri Kecil dan Sederhana (IKS), tetapi, gagal masuk ke pasaran luar. Hal ini disebabkan oleh penampilan pembungkusan yang kurang menarik dan pembungkusan yang tidak mencapai piawaian yang ditetapkan. Selain itu, penggunaan bahan pembungkusan yang tidak tepat dan kaedah pembungkusan yang tidak efektif mengurangkan jangka hayat produk. Oleh itu, penting bagi usahawan IKS untuk mempunyai ciri pembungkusan yang berinovatif bagi meningkatkan jualan dan jangka hayat produk. Keupayaan inovasi pembungkusan dijangka didorong oleh faktor PSiKKIT iaitu pengetahuan, sikap, kesedaran, kewangan, jaringan institusi dan teknologi. Fokus kajian ini adalah menganalisis kajian literatur yang lalu mengenai faktor-faktor PSiKKIT yang mendorong usahawan untuk menghasilkan pembungkusan yang berinovasi. Dapatan kajian mendapati, faktor PSiKKIT boleh mendorong usahawan IKS untuk lebih kreatif dan berinovasi di dalam pembungkusan makanan. Pengaruh PSiKKIT adalah sejajar dengan aplikasi hujah teori Tingkah laku dirancang (TPB) bagi meramalkan tingkah laku yang disengajakan. Tingkah laku boleh dirancang dengan beranggapan bahawa perilaku manusia berlaku dalam keadaan yang sedar dan mempertimbangkan segala informasi yang tersedia. Oleh itu, dapat disimpulkan bahawa faktor PSiKKIT boleh dijadikan sebagai alat untuk memotivasikan usahawan IKS menghasilkan pembungkusan produk yang berinovatif bagi meningkatkan prestasi pasaran dengan lebih strategik. Selain itu, maklumat yang diperoleh daripada kesusasteraan telah meningkatkan pemahaman dengan lebih mendalam mengenai bagaimana TPB dapat diintegrasikan dalam bidang pemasaran.
\end{abstract}

Kata kunci: amalan, inovasi, pembungkusan, pengetahuan, teori Tingkah Laku Dirancang (TPB), usahawan IKS 


\title{
PSiKKIT factors: Drivers of packaging innovation among food companies within the Small and Medium Industries
}

\begin{abstract}
Food product packaging plays a pivotal role in attracting the customers. There are many quality products produced by Small and Medium Industry (SMI) entrepreneurs which had failed to penetrate the market. The situation is due to the unattractive packaging appearance and does not meet packaging standards. Moreover, the use of imprecise packaging materials and ineffective packaging methods may have shorten the lifespan of the products. Therefore, it is important for SMI entrepreneurs to embark on innovative packaging features in order to increase their sales and products' life span. Entrepreneurs' innovative capability normally can be assumed to be driven by PSiKKIT factors, which comprise of the knowledge, attitudes, awareness, financial, institutional networking and technology. The focus of this study is to analyze previous literatures pertaining to the PSiKKIT factors which had drived entrepreneurs towards innovative packaging. The finding in the present study indicates that PSiKKIT factors can motivate SMI's entrepreneurs to be more creative and innovative in food packaging. The PSiKKIT factors are parallel with the application of Theory of Planned Behavior (TPB) argument that used to deliberate the act of intended human behaviors. The behaviors can be planned assuming all human behaviors occurred consciously and by considering available information. Thus, in can be conclude that the PKiKKIT factors can be a necessary tools that can motivate the SMI's entrepreneurs to create their product packaging innovatively that would strategically improve their market performance. Moreover, the information gathered from the literature has improve our basal understanding on how TPB can be integrated in the marketing field.
\end{abstract}

Keywords: practice, innovation, packaging, knowledge, Theory of Planned Behavior (TPB), SME entrepreneurs

\section{Pengenalan}

Realiti yang berlaku di dalam dunia pemasaran, pengguna mempunyai masa tiga hingga tujuh saat dalam pandangan pertama secara visual untuk mendorong pengguna tertarik kepada penampilan luaran sesuatu produk terlebih dahulu sebelum terdorong untuk membeli. Pembungkusan ialah salah satu alat pemasaran strategik untuk mencipta imej produk secara visual pada pandangan pertama pengguna. Hal ini menunjukkan pembungkusan adalah sangat penting untuk mempengaruhi emosi, persepsi dan memastikan pelanggan kembali lagi untuk membeli. Sedikit inovasi yang dilakukan pada pembungkusan seperti sesuatu yang istimewa, unik, kreatif, mudah dibuka, mempunyai ciri-ciri keselamatan, berinformasi dan boleh diguna semula membantu menarik pengguna untuk memiliki produk berkenaan. Penambahbaikan pembungkusan, walaupun kecil akan memberi impak perubahan yang ketara di dalam penjualan dan meningkatkan pendapatan syarikat (Kotler \& Armstrong, 2012).

Amalan atau perilaku IKS dalam menghasilkan pembungkusan yang inovatif turut dipengaruhi beberapa faktor seperti sikap, norma subjektif dan kawalan perilaku yang 
menentukan kecenderungan usahawan dalam amalan. Kajian lepas membincangkan pelbagai faktor yang berkaitan dengan cabaran dan halangan usahawan IKS dalam perniagaan, diantaranya adalah sumber kewangan yang tidak mencukupi, modal insan yang kurang kemahiran, kurang berdaya saing di dalam perniagaan, infrastruktur yang terhad dan disebabkan polisi kerajaan (Md Nor et al., 2016). Cabaran ini turut disokong oleh Adigun (2016) yang menyatakan modal adalah salah satu halangan utama yang dihadapi oleh IKS dalam membangunkan inovasi pembungkusan. Kemelut ini turut dihadapi oleh IKS di Thailand yang turut berhadapan dengan limitasi kewangan dan persekitaran luaran (Chittithaworn et al., 2011). Cabaran dari aspek kemahiran, pengetahuan teknologi, dan dasar kerajaan semasa turut dihadapi oleh usahawan IKS di Korea (Choi \& Lim, 2017). Menurut Deshati (2016) pula, faktor penghalang yang dihadapi oleh IKS di Albania adalah kos ekonomi yang tinggi untuk melakukan inovasi dan kesederhanaan pengetahuan untuk melaksanakan inovasi.

Industri kecil dan sederhana telah diiktiraf sebagai enjin untuk pertumbuhan ekonomi dan membantu menjana peluang pekerjaan. Namun, IKS turut dipengaruhi oleh cabaran-cabaran dari persekitaran perniagaan yang mempengaruhi prestasi mereka (Chin \& Harizan, 2017; Mohd Hafeez Al-Amin et al., 2016). Berdasarkan kajian-kajian lepas, majoriti IKS gagal merealisasikan pentingnya jenama dan kualiti pembungkusan (Wang \& Shapira, 2012; Kiumarsi et al., 2014) dan punca kepada IKS sukar untuk bertahan di pasaran yang kompetitif. Sebagai perbandingan, kajian sebelumnya banyak membincangkan cabaran yang dihadapi dalam meningkatkan kualiti produk dan perniagaan seperti penggunaan teknologi (AlBar \& Hoque, 2017; Ionica \& Razvan, 2010; Kumlachew, 2015; Suwardi Afandi et al., 2016); prestasi IKS (Sayal \& Banerjee, 2017); hubungan pekerja; pengurusan operasi (Mohd Amy Azhar \& Safiah, 2017); dan pembangunan produk hijau (Noor Hidayah et al., 2018). Malah, kajian berkaitan pembungkusan produk makanan juga banyak memfokuskan dari sudut kajian terhadap pengguna dalam membuat keputusan untuk membeli (Azad \& Masoumi, 2012; Beneke et al., 2015; Kurtkoti, 2016; Siti Hasnah et al., 2012; Tinne, 2016; Zekiri \& Hasani, 2015). Kajian lepas menunjukkan terdapat banyak faktor yang boleh membawa kepada kejayaan atau kegagalan sesebuah perniagaan termasuk faktor persekitaran dalaman dan luaran (Alfoqahaa, 2018; Atiqah et al., 2016; Islam \& Muktadir-Al-Mukit, 2016; Jernström et al., 2017; Sayal \& Banerjee, 2017; Suhaila et al., 2014). Malah, kajian yang dijalankan juga tidak banyak membincangkan faktor yang mempengaruhi amalan terhadap pembungkusan.

Kajian ini penting untuk dilaksanakan sebab penambahbaikan amalan dalam inovasi pembungkusan produk akan membantu meningkatkan pemasaran produk. Kajian lanjutan bagi menganalisis tingkah laku usahawan perlu dilakukan bagi melihat hubungan sikap, norma subjektif dan kawalan perilaku terhadap amalan pembungkusan. Penerokaan lebih lanjut mengenai amalan unsur pemasaran keusahawanan dalam mencapai tahap prestasi yang lebih tinggi dengan menganalisis amalan perniagaan semasa mereka (Kalsonm \& Ab. Rahim, 2015). Peningkatan tahap pengetahuan usahawan di dalam memperbaiki kualiti pembungkusan akan mengubah sikap dan kecenderungan usahawan untuk menghasilkan pembungkusan yang berkualiti. Kajian ini perlu dilakukan untuk menilai tahap pengetahuan usahawan dalam meningkatkan peluang pembangunan perniagaan bagi label dan inovasi produk dari segi pembungkusan, bentuk dan kandungan (Ariciu, 2016). Usahawan IKS perlu membuat penambahbaikan terhadap pembungkusan seperti imej produk, penggunaan warna dan informasi pada pembungkusan bagi meningkatkan reputasi imej produk dan perniagaan. Berdasarkan kajian literatur terdapat pelbagai faktor yang menyebabkan dan menghalang inovasi itu berlaku. Kajian ini perlu dilakukan bagi menganalisis faktor pendorong 'PSiKKIT' yang memberikan 
maksud iaitu P (Pengetahuan), Si (Sikap), K (Kesedaran), K (Kewangan), I (Jaringan Institusi); dan $\mathrm{T}$ (Teknologi) yang mungkin mempengaruhi usahawan untuk menghasilkan pembungkusan yang berinovatif.

Masih terdapat jurang kajian mengenai isu pembungkusan yang melibatkan usahawan IKS terutamanya berskala mikro yang perlu dikaji dan dilihat dengan lebih terperinci dari aspek amalan semasa usahawan di dalam inovasi pembungkusan produk makanan. Persoalan yang timbul, jika usahawan IKS ingin melakukan inovasi pada pembungkusan produk semasa, apakah faktor yang mendorong usahawan IKS untuk berbuat demikian? Objektif kajian ini adalah menganalisis faktor pendorong PSiKKIT yang mempengaruhi amalan pembungkusan dalam kalangan usahawan kecil sektor makanan.

Oleh itu, artikel ini membincangkan faktor PSiKKIT yang menjadi pendorong IKS berskala mikro dalam amalan pembungkusan dari perspektif dan dimensi pengetahuan, sikap terhadap kecenderungan perilaku dan tahap kesedaran IKS terhadap kepentingan pembungkusan. Faktor sokongan lain ialah kewangan, jaringan industri dan teknologi yang mendorong amalan usahawan IKS dalam pembungkusan.

\section{Kajian literatur}

\section{Teori Tingkah Laku Dirancang (TPB)}

Teori Tingkah Laku Dirancang (Ajzen, 2005) (Rajah 1) yang mendasari perbincangan ini menerangkan niat untuk berperilaku dipengaruhi oleh tiga faktor penentu iaitu sikap, norma subjektif, dan kawalan perilaku. Teori ini menjelaskan tentang perilaku manusia yang menyatakan bahawa prestasi individu bagi tingkah laku tertentu di tentukan pada asasnya oleh kehendak individu (niat) untuk melakukan tingkah laku berkenaan. Niat untuk berperilaku merupakan kombinasi daripada sikap, perilaku dan norma subjektif. Hasil kajian Bahadur Ali dan Naimatullah (2015) mendapati satu korelasi yang tinggi di antara niat keusahawanan dan sikap usahawan IKS terhadap tingkahlaku. Teori ini meramalkan tingkah laku yang disengajakan, kerana tingkah laku boleh dibincangkan dan dirancang dengan beranggapan bahawa perilaku manusia berlaku dalam keadaan yang sedar dan mempertimbangkan segala informasi yang tersedia. Penggunaan teori ini banyak digunakan dalam pelbagai bidang seperti pengurusan sumber daya manusia, pemasaran dan dalam penelitian sosial.

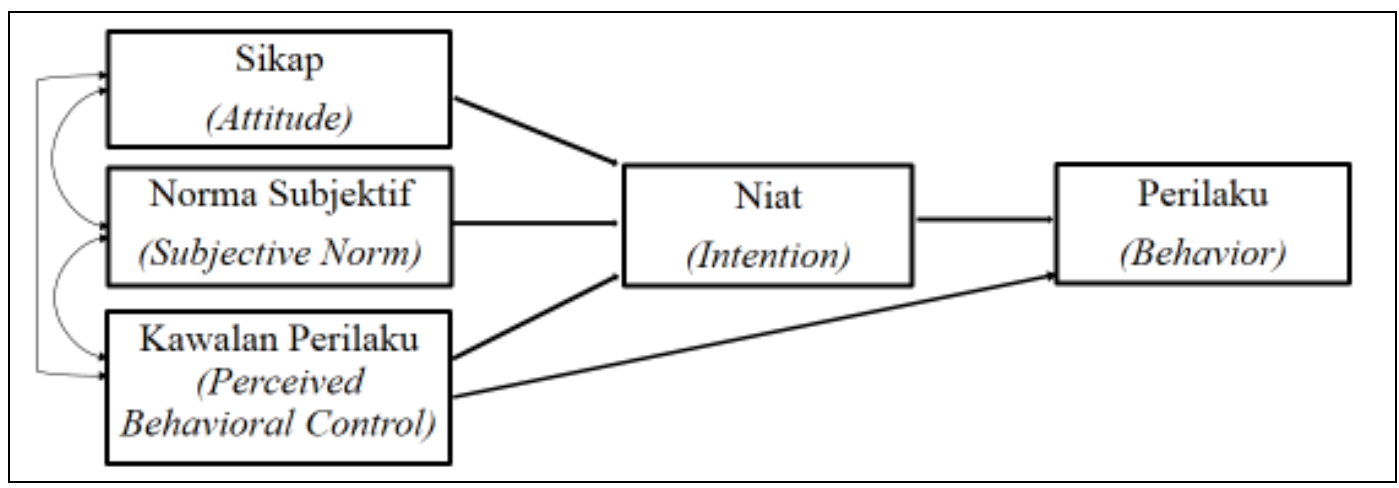

Rajah 1. Teori Tingkah Laku Dirancang (Ajzen, 2005) 
Kajian yang dijalankan Diana-Rose et al. (2016) jelas menunjukkan IKS perlu meningkatkan pembungkusan makanan kerana kajian terhadap kesedaran pengguna menunjukkan mereka lebih suka memilih produk berkualiti. Walau bagaimanapun, jika tidak ada peluang untuk mengetahui kualiti sesuatu produk itu, maka, pengguna akan merujuk kepada pembungkusan dan penjenamaan. Oleh sebab itu, pembungkusan lebih mempengaruhi pengambilan keputusan untuk memliki produk. Pembungkusan yang baik akan mencerminkan lebih positif dalam tingkah laku pembelian pengguna. Manakala, Esa et al. (2002) mendapati pengetahuan, amalan dan sikap peniaga kecil yang menjadi responden kajian yang dijalankan terhadap etika perniagaan adalah sederhana. Dapatan tersebut secara tidak langsung menunjukkan bahawa tingkah laku manusia adalah bersifat terancang dan dipengaruhi oleh elemen kognitif dan afeksi seperti pengetahuan dan sikap termasuk juga dalam konteks tingkah laku inovasi pembungkusan dalam kalangan usahawan. Dalam kajian ini, tahap amalan usahawan dalam menghasilkan inovasi pembungkusan dilihat dan dikaji. Amalan atau tingkah laku seseorang usahawan untuk melaksanakan pembungkusan yang berinovasi adalah dipengaruhi oleh niat atau kecenderungan untuk melaksanakannya. Kecenderungan ini dipengaruhi oleh faktor sokongan institusi dan individu yang bertindak sebagai kawalan terhadap perilaku, sikap dan norma subjektif. Faktor seperti kekurangan sumber kewangan, kurangnya jaringan institusi dan kekurangan teknologi akan menyebabkan amalan pembungkusan yang menarik terkesan. Usahawan IKS yang mempunyai matlamat dan visi yang ingin dicapai, didapati mempunyai hubungan positif dan signifikan dengan hasrat mereka untuk bekerjasama dengan pelbagai institusi (Mohd Hizam \& Usman, 2016).

\section{Evolusi pembungkusan dalam campuran pemasaran}

Campuran pemasaran telah ditakrifkan sebagai set alat pemasaran yang digunakan firma untuk meneruskan objektif pemasarannya dalam sasaran. Asas pemasaran bermula dengan model campuran pemasaran (marketing mix) yang memfokuskan kepada empat perkara asas (4P's) iaitu produk, promosi, tempat dan harga. Salah satu elemen di bawah faktor produk, terdapat elemen pembungkusan yang merujuk kepada item yang sebenarnya dijual. Evolusi pemasaran yang berlaku telah meletakkan pembungkusan sebagai salah satu elemen dalam lapan perkara di dalam campuran pemasaran (8P's). Hal ini menunjukkan pembungkusan sebagai salah satu elemen penting di dalam pemasaran.

Kaji selidik pembungkusan yang dijalankan terhadap usahawan di Amerika Syarikat, lebih daripada $80 \%$ usahawan menyatakan pembungkusan memainkan peranan penting untuk memastikan kejayaan jenama mereka (Anon, 2018). Secara amnya, fungsi pembungkusan adalah untuk melindungi produk daripada faktor kerosakan yang disebabkan oleh perubahan suhu, kelembapan, pencemaran, kerosakan mekanikal dan memudahkan proses pengangkutan. Kini, pembungkusan bukan sekadar untuk melindungi produk dari sebarang kerosakan, malahan pembungkusan adalah 'jurujual' dan media komunikasi yang mampu untuk membawa syarikat pengeluar produk untuk menikmati keuntungan jualan. Wyrwa dan Barska (2017) menyatakan ciri-ciri pembungkusan yang paling penting bagi pengguna adalah keselesaan penggunaan dan ketahanan. Magnier et al. (2016) pula mendapati, kualiti produk makanan yang mempunyai pembungkusan menarik memberikan persepsi yang lebih positif kepada pengguna berbanding apabila ia dibungkus dalam pembungkusan konvensional. Ini bagi memastikan produk yang dihasilkan adalah berbeza dengan produk pesaing supaya ianya kekal relevan untuk berada di pasaran. 


\section{Pembungkusan rahsia kuasai pasaran}

Pembungkusan bukan sahaja berfungsi untuk melindungi produk dari sebarang kerosakan, tetapi juga berperanan sebagai alat pemasaran untuk menarik pembeli. Oleh itu, beberapa aspek perlu diambilkira dalam menentukan kaedah pembungkusan supaya berbeza dengan pesaing, di antaranya adalah penggunaan visual (rekabentuk, warna, grafik dan sebagainya) yang dapat mempromosikan produk dan memberikan kesan yang baik kepada pengguna.

Kajian kes yang dijalankan oleh Kiumarsi et al. (2014) mencadangkan usahawan perlu memperbaiki imej pembungkusan, dan membuat inovasi produk untuk kekal di dalam pasaran. Justeru itu, untuk kekal berdaya tahan, IKS perlu berinovasi di dalam menghasilkan produk yang berkualiti dan imej produk yang menarik. Menurut Sazrinee et al. (2014), penyusunan semula jenama, pembungkusan, strategi pemasaran dan penggunaan teknologi tepat dapat membawa produk ke pasaran global. Imej produk IKS yang perlu difokuskan adalah inovasi pembungkusan yang menarik dan kreatif, label, jenama, logo, gambar, slogan, warna, bentuk, saiz, nilai, edisi khas, pembungkusan hijau dan lain-lain. Penciptaan imej produk akan memberikan imej yang lebih baik kepada syarikat dan produk untuk terus kekal berdaya tahan di pasaran yang kompetitif. Ampuero dan Vila (2006) pula mempersoalkan pengaruh respon pengguna terhadap imej yang ditonjolkan di dalam pembungkusan produk. Mereka mengenalpasti pemboleh ubah seperti warna, tipografi, grafik, gambar, status, nilai, keunggulan, keselamatan, prinsip kualiti yang terdapat persepsi pengguna terhadap produk. Hasil kajian yang dijalankan mendapati, bagi memastikan kesan yang dikehendaki dapat dicapai, kombinasi elemen-elemen ini adalah perlu. Imej pembungkusan boleh mempengaruhi pengguna untuk membeli produk dan pernyataan ini turut disokong oleh Wells et al. (2007) yang mengkaji mengenai kepentingan pembungkusan bagi produk makanan.

IKS mewakili 98.5\% daripada keseluruhan perusahaan yang ditubuhkan di Malaysia. Walau bagaimanapun, $76.5 \%$ daripada IKS merupakan perusahaan mikro, $21.2 \%$ perusahaan kecil dan $2.3 \%$ perusahaan sederhana yang lazimnya menggambarkan kekurangan modal dan keupayaan untuk berkembang (SME Corporation, 2018). Dalam kalangan usahawan IKS pemprosesan makanan terutamanya yang berskala mikro, kelemahan yang paling ketara adalah dari aspek pembungkusan. Ini dapat dilihat melalui produk yang dibungkus didapati tidak mempunyai imej yang menarik dan penggunaan bahan pembungkus yang kurang sesuai (Ahmad Zaki, 2011). Sebagai contoh, penggunaan plastik satu lapis seperti polipropilena (PP) oleh usahawan kerepek, rempeyek, keropok bergoreng, dan sebagainya yang digunakan untuk membungkus produk makanan berkenaan. Seringkali dilihat produk yang dibungkus dengan plastik ini kerap kali tidak tahan lama, cepat lembik, berbau tengik dan pembungkusan yang digunakan kurang menarik. Masalah ini boleh diatasi dengan menggunakan teknologi seperti pembungkusan bernitrogen dan pembungkusan dengan bahan penyerap oksigen seperti yang disyorkan oleh MARDI kerana telah terbukti dapat memanjangkan tempoh hayat produk (Mohd Arif, 2008). Dari segi pengetahuan usahawan berkaitan peranan dan fungsi pembungkusan di dalam aspek pengiklanan, didapati usahawan kurang memberi perhatian dan keutamaan terutamanya responden lelaki dan latarbelakang pendidikan yang rendah (Suwardi Afandi \& Mohd Arif, 2014). Ini antara faktor yang menyebabkan corak dan reka bentuk pembungkusan usahawan bersaiz mikro kelihatan tidak menyerlah dan kurang menarik. Usahawan IKS juga berpendapat, asalkan produk itu menarik dan berkualiti ianya sudah memadai dan mereka juga beranggapan bahawa pembungkusan produk adalah tidak relevan (Vivine, 2018). 
Usahawan juga perlu bersikap proaktif dalam mencari maklumat dan bimbingan untuk membantu mereka meningkatkan pengetahuan dalam aspek pembungkusan. Dalam era dunia tanpa sempadan dan kadar capaian jalur lebar yang semakin baik, isu mendapatkan maklumat terkini berkaitan pemasaran dan pembungkusan seharusnya dapat diatasi dengan menggunakan teknologi komunikasi maklumat (ICT). Penggunaan teknologi ini akan memudahkan pencarian maklumat pemasaran dengan cepat dan pada kos yang rendah. Maklumat pemasaran seperti produk, kaedah pembungkusan, harga, kaedah promosi dan lain-lain yang tidak dianggap "sulit" dari pesaing lain membolehkan sesebuah perniagaan membuat perbandingan produk yang ditawarkan dengan produk pesaing dan seterusnya merancang strategi yang sesuai untuk menghasilkan produk yang berbeza dari pesaing (Baharuddin, 2009). Strategi ini akan memberikan impak yang positif di dalam perniagaan dan pemasaran kerana produk yang dihasilkan adalah berbeza dan unik. Namun begitu, terdapat pelbagai cabaran lain yang terpaksa ditempuhi oleh IKS di dalam memastikan perniagaan terus berdaya tahan.

\section{Metod kajian}

Kajian ini merupakan sebuah sorotan karya lepas yang memperihalkan mengenai kepentingan inovasi pembungkusan dalam era pasaran masa kini. Sehubungan itu, kajian ini telah menggunakan kaedah kajian yang merangkumi penelitian ke atas karya lepas dan mengartikulasi karya tersebut bagi memperihalkan fenomena kajian. Pencarian literatur berkaitan dilakukan dengan menggunakan beberapa katakunci utama iaitu usahawan IKS, inovasi pembungkusan, cabaran, dorongan, isu IKS, persepsi terhadap IKS dan kejayaan IKS. Pencarian perpustakaan terdiri daripada bahan dalam talian dan offline dari arikel dalam jurnal hingga artikel dalam buku dan menggunakan perisian Mendeley. Carian artikel dihadkan kepada tempoh penerbitan di antara tahun 2002 hingga terkini. Faktor yang mempengaruhi IKS tidak terhad kepada IKS di Malaysia sahaja tetapi ia juga mengambilikira hasil kajian seumpama berkaitan IKS di luar negara. Faktor-faktor pendorong yang diperolehi dianalisis dengan cara dikumpulkan dan di susun mengikut tema yang sesuai dan pada kelompok yang sama disatukan.

\section{Hasil kajian dan perbincangan}

Cabaran yang dihadapi oleh usahawan IKS adalah berbeza mengikut negara. Walaupun kebanyakkan usahawan IKS menghadapi masalah kewangan sebagai cabaran utama dalam melaksanakan inovasi, namun, terdapat cabaran lain yang merupakan cabaran sebenar yang dihadapi oleh usahawan IKS. Usahawan IKS di seluruh negara juga menghadapi isu yang sama terutamanya persaingan produk di pasaran antarabangsa. Bagi memastikan IKS terus kekal relevan dan terus diperkasa sama ada di dalam negara mahupun di pasaran global, inovasi pembungkusan dan persembahan produk adalah penting. Produk yang diinovasikan mempunyai hubungan yang signifikan dengan identiti perniagaan dan ini menunjukkan bahawa inovasi produk sememangnya memainkan peranan penting bagi sesebuah syarikat untuk membangunkan identiti perniagaan yang kukuh (Hanaysha et al., 2014). Usahawan IKS perlu memperbaiki imej pembungkusan, dan membuat inovasi dengan mempelbagaikan variasi produk jika ingin terus kekal di dalam pasaran yang sangat kompetitif pada hari ini. Ini turut disokong oleh dapatan kajian Kiumarsi et al. (2014). 
Oleh itu, usahawan IKS perlu membuat perancangan dan penambahbaikan amalan semasa bagi memastikan perniagaan dan produk yang dihasilkan sentiasa diterima oleh pengguna dan secara tidak langsung perniagaan dapat berdaya tahan. Peningkatan tahap kesedaran berkaitan penampilan setiap produk yang dihasilkan perlu dititikberatkan dari segi pembungkusan, imej dan kualiti produk bagi menarik perasaan, emosi dan jiwa pengguna untuk membeli produk secara berterusan. Usahawan IKS perlu berinovasi di dalam menghasilkan produk yang berkualiti dan imej pembungkusan produk yang menarik dan kreatif mengikut sasaran pengguna untuk terus kekal berdaya tahan di pasaran yang kompetitif. Penampilan umum seperti daya tarikan visual dan kapasiti pembungkusan mempunyai pengaruh yang signifikan untuk menarik perhatian pengguna dalam keputusan pembelian.

Walau bagaimanapun, kuasa pembungkusan dengan penggunaan imej yang kreatif mampu menarik perhatian pengguna secara visual sehingga mempengaruhi keputusan akhir dalam pembelian. Pembungkusan inovatif sebenarnya boleh menambah nilai kepada produk jika ia memenuhi keperluan dan perletakan produk pada pengguna yang tepat. Kegagalan meletakkan pembungkusan produk pada kedudukan dan sasaran yang tepat menyebabkan produk berkenaan sukar untuk menembusi pasaran antarabangsa mahupun bersaing dengan produk tempatan yang telah pun mempunyai jenama yang kukuh di pasaran. Keupayaan inovasi IKS secara positif berkait rapat dengan prestasi inovasi teknologi, pengetahuan dan kemahiran serta keupayaan IKS untuk melakukan perubahan adalah faktor kontekstual yang mempengaruhi secara positif prestasi inovasi pembungkusan mereka. Pembungkusan mempunyai pengaruh yang terbukti penting terhadap keputusan pembelian dalam persekitaran runcit.

\section{Faktor PSiKKIT mendorong amalan IKS dalam inovasi pembungkusan}

Bagi menghasilkan rangka kerja konseptual ini, penyelidikan kualitatif dilaksanakan untuk mengesahkan dan menggambarkan rangka kerja ini. Pengetahuan, sikap dan kesedaran dikelompokkan dalam faktor individu dan kewangan, jaringan institusi dan teknologi pula dikelompokkan dalam faktor sokongan. Kesemua faktor pendorong ini mempengaruhi niat atau kecenderungan seseorang usahawan dalam tindakan perilaku dan amalan dalam pembungkusan produk. Merujuk kepada kajian yang dijalankan oleh (Bahadur Ali \& Naimatullah, 2015) yang meneroka sikap dan niat individu untuk terlibat dalam keusahawanan, mengesahkan teori TPB (Ajzen 1991, 2005) sesuai digunakan dengan konteks negara membangun di mana individu boleh mengembangkan niat mereka untuk terlibat di dalam keusahawanan melalui faktor-faktor seperti keperluan untuk pencapaian, inovasi dan harga diri.

Pengetahuan terhadap perilaku boleh mempengaruhi keputusan atau tindakan manusia (McEachern \& Warnaby, 2008). Hubungan antara pengetahuan dan tingkah laku pengguna dapat dijelaskan dengan baik menerusi teori TPB (Ajzen, 1991; 2005). Berdasarkan TPB, sikap dan kepercayaan individu dibentuk oleh pengetahuan. Menurut McEarchern dan Warnaby (2008), pengetahuan dapat dibahagikan kepada sistem pengetahuan, pengetahuan berkaitan tindakan dan pengetahuan yang berkesan. Kajian Suraiya et al. (2018) mendapati peningkatan pengetahuan dan kemahiran dalam subjek perdagangan dan perakaunan di kalangan pelajar sekolah boleh mengubah dan membentuk tingkah laku seseorang individu dalam perniagaan. Dalam kajian ini, pengetahuan usahawan dikaitkan dengan pengetahuan berkaitan teknologi dan pembungkusan, segmentasi perletakan produk terhadap pengguna, perletakan imej dan informasi pada pembungkusan. Usahawan yang mempunyai tahap pengetahuan yang baik di dalam bidang pembungkusan makanan akan menunjukkan kecenderungan ke arah amalan pembungkusan yang 
lebih baik. Peningkatan pengetahuan dan kemahiran dalam inovasi pembungkusan di kalangan usahawan boleh mengubah perilaku dan amalan dalam perniagaan.

Sikap terhadap perilaku adalah keupayaan usahawan IKS untuk berubah dalam amalan pembungkusan sedia ada. Kajian Zainol dan Kamil (2009) menunjukkan sikap adalah salah satu faktor penentu niat di dalam gelagat kepatuhan zakat gaji di kalangan masyarakat Islam di negeri Kedah. Safaie et al. (2016) juga meletakkan sikap sebagai faktor penerimaan e-pembelajaran di kalangan agen pengembangan pertanian dalam sektor pertanian di Malaysia. Dalam kajian ini, kecenderungan sikap yang berkait rapat dengan tahap motivasi usahawan untuk terus mempertingkatkan perniagaan yang dilakukan dan menghasilkan sesuatu yang luar biasa. Niat adalah diharapkan untuk mempengaruhi tahap prestasi seseorang itu yang mempunyai kawalan tingkah laku sehingga seseorang itu bermotivasi untuk mencuba dan melakukan perubahan. Sebaliknya, kecenderungan sikap usahawan yang kurang bermotivasi dan ketiadaan jangkaan hasil seperti pembungkusan yang tidak menarik akan terhasil.

Kesedaran terhadap perilaku adalah kecenderungan kepada tingkah laku yang berorientasikan tindakan. Menurut Chartrand (2005) kesedaran pengguna (sama ada secara sedar atau tidak sedar) mendahului kawalan, pengubahsuaian, penghapusan dan perubahan dalam tingkah laku manusia dan keputusan. Kajian Suraiya dan Nur Faridah (2012) mendapati kurangnya kesedaran dan kurangnya pengetahuan mengenai hak pengguna dan prosedur tuntutan menyebabkan pengguna tidak berupaya untuk mempertahankan diri daripada pedagang yang licik dalam penipuan. Hasil analisis menunjukkan terdapat hubungan yang signifikan antara kesedaran pengguna dengan tingkahlaku pengguna yang berkesan. Oleh itu, pengguna yang berkesan tingkah laku hanya dapat dicapai melalui kesedaran. Dalam kajian ini, tahap kesedaran usahawan terhadap kepentingan dan peranan pembungkusan akan menghasilkan kualiti pembungkusan sama ada berinovasi atau tidak. Pembungkusan yang mempunyai ciri-ciri inovasi berupaya memastikan sesebuah perniagaan terus berdaya saing di pasaran.

Faktor kewangan, jaringan institusi dan teknologi terhadap perilaku (kawalan perilaku) adalah faktor sokongan yang mempengaruhi kecenderungan terhadap tingkah laku. Kajian kes yang dijalankan oleh Alauddin Sidal (2014) terhadap usahawan wanita mendapati usahawan wanita yang berjaya dalam perniagaan memiliki keutuhan motivasi diri, komitmen yang tinggi, pengetahuan dan kemahiran, keupayaan mengurus sumber seperti kewangan, pekerja dan bahan mentah; serta kemampuan menguasai pasaran. Bantuan dana kewangan yang diberikan oleh agensi kerajaan kepada usahawan Malaysia merupakan faktor pendorong individu untuk menyertai bidang keusahawanan (Zafir \& Fazilah, 2017). Kewangan dalam konteks kajian ini adalah agihan kewangan yang diperuntukkan untuk inovasi pembungkusan, dan sumber dana kewangan. Kejayaan sukar dicapai sekiranya usahawan tidak memiliki kesedaran untuk pengurusan kewangan yang cekap. Disiplin dalam menguruskan kewangan perniagaan akan mengutuhkan perniagaan untuk berdaya saing di pasaran. Sekiranya usahawan mempunyai produk yang berkualiti sekalipun, tetapi tiada kemahiran di dalam pengurusan kewangan yang cekap, mereka akan menghadapi masalah terutamanya di dalam mengembangkan produk di pasaran luar.

Menyedari kepentingan IKS di Malaysia, kerajaan telah menubuhkan pelbagai institusi khusus untuk mengatasi masalah berkaitan usahawan. Tidak dapat dinafikan, kerajaan telah menyediakan pelbagai jaringan institusi dengan pelbagai jenis bantuan dan kemudahan kepada IKS seperti kawalan kualiti produk, pembangunan reka bentuk produk, pembungkusan, promosi dan pemasaran. Bantuan yang diberikan membantu usahawan menghasilkan produk dengan pek pembungkusan yang berinovasi. Hal ini bagi memastikan usahawan IKS di Malaysia mampu 
memasarkan produk yang berkualiti dan mampu bersaing dengan pesaing hingga ke pasaran global. Ragayah dan Rahmah (2004) mendapati segelintir sahaja pengusaha yang berjaya mendapatkan perkhidmatan yang ditawarkan oleh agensi. Jenis bantuan yang diterima kebanyakkannya dalam bentuk kawalan kualiti, promosi dan mendapatkan kontrak. Tidak ramai pengusaha yang mendapatkan bantuan dari institusi berkaitan rekabentuk dan pembungkusan. Malah, sebahagian pengusaha tidak menggunakan sebarang kemudahan bantuan daripada institusi disebabkan oleh pelbagai alasan. Oleh itu, jaringan institusi ini dilihat sebagai salah satu faktor yang penting bagi melihat bentuk perkhidmatan yang diperolehi oleh usahawan IKS terutamanya berkaitan pembungkusan.

Masalah teknikal yang paling utama dihadapi oleh IKS adalah berkaitan dengan teknologi pemprosesan dan peningkatan kualiti produk untuk terus berdaya saing (Sharina et al., 2013). Hasil kajian Suraiya et al. (2015) yang mendapati aktiviti inovasi di kalangan usahawan pemprosesan makanan berskala kecil sederhana masih di peringkat perlahan. Inovasi pembungkusan yang lebih berdaya tahan dan sesuai dengan sifat makanan amat diperlukan dan perlu disokong oleh bantuan teknologi dan kewangan. Oleh itu, teknologi adalah faktor sokongan yang penting kerana berkait rapat dengan kewangan dan jaringan institusi. Teknologi dalam konteks kajian ini dilihat dari aspek penggunaan teknologi tertentu dalam menghasilkan pembungkusan seperti penggunaan alatan atau mesin khas, dan perubahan rekabentuk pembungkusan. Umumnya, penggunaan teknologi dalam kalangan pengusaha industri kecil dan sederhana (IKS) agak terhad. Mereka memerlukan modal yang agak besar untuk membeli mesin yang bersesuaian. Bagi menghasilkan pembungkusan yang berinovasi, usahawan perlu mempunyai pengetahuan produk, asas teknologi pembungkusan dan asas grafik pembungkusan untuk diterjemahkan kepada pereka grafik yang diupah bagi merealisasikan rekaan yang diingini dan memenuhi citarasa pengguna.

Faktor kontekstual seperti teknologi, pengetahuan, kemahiran, dan sikap berkait rapat dengan prestasi yang berupaya mempengaruhi inovasi IKS secara positif (Mahani et al., 2018). Faktor pendorong ini menyebabkan usahawan menghasilkan pembungkusan yang sedemikian. Ajzen (1991) berpendapat bahawa model yang dibina secara asasnya, terbuka untuk menambahkan pemboleh ubah lain jika terdapat keperluan yang signifikan mengikut kajian dan situasi terhadap niat atau perilaku (Yazdanpanah \& Forouzani, 2015). Oleh itu, berdasarkan kajian literatur dan teoritikal yang mendalam, faktor PSiKKIT berupaya untuk mendorong perubahan yang dinamik di dalam menghasilkan pembungkusan yang berinovasi.

\section{Kesimpulan}

Amalan usahawan dalam menghasilkan produk yang mempunyai ciri-ciri pembungkusan berinovasi dapat meningkatkan kejayaan peluang pasaran dengan lebih baik. Secara keseluruhan, artikel ini telah berjaya untuk mengenalpasti faktor PSiKKIT yang mendorong usahawan IKS dalam menghasilkan pembungkusan yang berinovasi dan dapat membantu usahawan IKS untuk lebih berjaya di dalam memasarkan produk hingga ke pasaran antarabangsa. Dalam kajian ini, tahap amalan usahawan dalam menghasilkan inovasi pembungkusan dilihat dan dikaji. Amalan atau tingkah laku seseorang usahawan untuk melaksanakan pembungkusan yang berinovasi adalah dipengaruhi oleh niat atau kecenderungan untuk melaksanakannya. Niat untuk berperilaku merupakan kombinasi daripada sikap, perilaku dan norma subjektif. Kecenderungan ini dipengaruhi oleh faktor sokongan institusi dan individu yang bertindak sebagai kawalan 
terhadap perilaku, sikap dan norma subjektif. Kesesuaian penggunaan teori TPB dalam kajian ini dapat meramalkan tingkah laku yang disengajakan, kerana tingkah laku boleh dibincangkan dan dirancang dengan beranggapan bahawa perilaku manusia berlaku dalam keadaan yang sedar dan mempertimbangkan segala informasi yang tersedia. Penggunaan teori TPB dalam bidang pemasaran dapat memperkayakan hasil penulisan ilmiah akademik.

Secara teorinya, faktor PSiKKIT ini adalah pemboleh ubah tidak bersandar yang penting untuk memastikan hubungan dengan amalan semasa usahawan IKS, tetapi data empirik diperlukan untuk membuktikan hubungan ini. Akibat kekurangan sumber kewangan, kurangnya jaringan institusi dan kekurangan teknologi menyebabkan amalan pembungkusan yang berinovasi terkesan. Walau bagaimanapun, artikel ini adalah kertas teoritikal, tiada data yang dikumpul untuk membolehkan diumumkan kepada pengkaji lain. Cadangan kajian pada masa akan datang adalah untuk menguji dan mengumpulkan data berdasarkan faktor PSiKKIT yang telah dikenal pasti sebagai faktor pendorong terhadap amalan usahawan IKS dalam inovasi pembungkusan.

\section{Rujukan}

Adigun, A. (2016). To investigate the influencing factors for sustainable packaging in a multinational SME supply chain. United Kingdom, University of Salford.

Ahmad Zaki, I. (2011). Formula usahawan berjaya. ( ${ }^{\text {st }}$ ed.). Kuala Lumpur, Utusan Publications \& Distributors Sdn Bhd.

Ajzen, I. (1991). The theory of planned behavior. Organizational Behavior and Human Decision Processes, 50(2), 179-211. Retrieved from https://www.sciencedirect.com

Ajzen, I. (2005). Attitudes, personality and behaviour.( $2^{\text {nd }}$ ed.). Poland, Open University Press.

Alauddin Sidal. (2014). Taksonomi keupayaan usahawan wanita Melayu. Journal of Human Capital Development, 7(2), 63-78.

AlBar, A.M., \& Hoque, M.R. (2017). Factors affecting the adoption of information and communication technology in small and medium enterprises: A perspective from rural Saudi Arabia. Information Technology for Development, 1-24. http://dx.doi.org/10.1080/02681102.2017.1390437

Alfoqahaa, S. (2018). Critical success factors of small and medium-sized enterprises in Palestine. Journal of Research in Marketing and Entrepreneurship 20(2), 170-188. https://doi.org/10.1108/JRME-05-2016-0014

Ampuero, O., \& Vila, N. (2006). Consumer perceptions of product packaging. Journal of Consumer Marketing, 23(2), 100-112.

Anon. 2018. Packaging Survey Analysis Executive Insights 2018. Retrieved from https://www.lek.com.

Ariciu, A.L. (2016). Marketing strategies for private brands in agro-food retail. Quality - Access to Success, 17, 415-419. https://doi.org/10.1093/bmb/ldt009

Atiqah, N., Binti, S., Nazri, A., \& Azmi, A. (2016). The challenges managing brand positioning: Small Medium Entreprises (SME) in Malaysia. International Journal of Business and Management Invention, 5(12), 2015-2016.

Azad, N. \& Masoumi, M. (2012). The impact of packaging on product competition. Management Science Letters, 2(8), 2789-2794.

Bahadur Ali, S., \& Naimatullah, S. (2015). Developing attitudes and intentions among potential 
entrepreneurs. Journal of Enterprise Information Management, 28(2), 304-322.

Baharuddin, I. (2009). Asas pengurusan pemasaran. Shah Alam, Selangor, Pusat Penerbitan Universiti (UPENA), Universiti Teknologi MARA.

Beneke, J., Mathews, O., Munthree, T., \& Pillay, K. (2015). The role of package colour in influencing purchase intent of bottled water: Implications for SMEs and entrepreneurs. Journal of Research in Marketing and Entrepreneurship, 17(2), 165-192. https://doi.org/10.1108/JRME-05-2015-0030

Chartrand, T.L. (2005). The role of conscious awareness in consumer behavior. Journal of Consumer Psychology, 15(3), 203-210. http://dx.doi.org/10.1207/\%0As15327663jcp1503_4

Chin, T.K., \& Harizan, S.H.M. (2017). Factors influencing consumers' purchase intention of cosmetic products in Malaysia. International Journal of Business and Innovation, 3(1), 1-15.

Chittithaworn, C., Islam, A., Keawchana, T., \& Yusuf, D.H.M. (2011). Factors affecting business success of small \& medium enterprises (SMEs) in Thailand. Asian Social Science 7(5), 180-190.

Choi, Y., \& Lim, U. (2017). Contextual factors affecting the innovation performance of manufacturing SMEs in Korea: A structural equation modeling approach. Sustainability 9(7), 1193. https://dx.doi.org/10.3390/su9071193

Deshati, E. (2016). Business strategies of SME's, innovation types and factors influencing their innovation: Albanian case. International Journal of Economics \& Management Sciences, 5(2), 1-6. http://dx.doi.org/10.4172/2162-6359.1000319

Diana-Rose, F., Zariyawati, M.A., Norazlina, K., Annuar, M.A., \& Manisah, O. (2016). Consumers' purchasing decision towards food products of small and medium enterprises. International Review of Management and Marketing, 6(4), 836-842.

Esa, A., Ab. Hadi, M.Y., \& Mohd Yunos, J. (2002). Prosiding Persidangan Kebangsaan Etika Gunaan dan Profesional. Bangi, UKM. 31-38.

Hanaysha, J., Hilman, H., \& Hasmini Abdul-Ghani, N. (2014). Direct and indirect effects of product innovation and product quality on brand image: Empirical evidence from automotive industry. International Journal of Scientific and Research Publications, 4(11), $1-7$.

Ionica, H. \& Razvan, O. (2010). Factors influencing innovation in Smes in Romania. Retrieved from https://www.reserachgate.net

Islam, N., \& Muktadir-Al-Mukit, D. (2016). Factors determining the success of SMEs in Bangladesh. https://doi.org/10.2139/ssrn.2851533.

Jernström, E., Karvonen, V., Kässi, T., Kraslawski, A., \& Hallikas, J. (2017). The main factors affecting the entry of SMEs into bio-based industry. Journal of Cleaner Production, 141(10), 1-10.

Kalsonm, A.W., \& Ab.Rahim, H. (2015). The understanding of small firm performance and the influence of entrepreneurial marketing on SMEs in Malaysia. Journal of Creative Writing, $1(3), 25-37$.

Kiumarsi, S., Jayaraman, K., Salmi, M.I., \& Varastegani, A. (2014). Marketing strategies to improve the sales of bakery products of small-medium enterprise (SMEs) in Malaysia. International Food Research Journal, 21(6), 2101-2107.

Kotler, P., \& Armstrong, G. (2012). Principles of marketing. (14 ${ }^{\text {th }}$ ed.). United States of America, Pearson Prentice Hall.

Kumlachew, M. (2015). Technology adoption of Ethiopian manufacturing firms: The case of textile and leather sector. Retrieved from http://etd.aau.edu.et 
Kurtkoti, A. (2016). Factors influencing consumer buying decision process for different products and brands. Sankalpa: Journal of Management \& Research, 6(1), 1-16.

Magnier, L., Schoormans, J., \& Mugge, R. (2016). Judging a product by its cover: Packaging sustainability and perceptions of quality in food products. Food Quality and Preference, 53, 132-142.

Mahani, A., Suraiya, I., \& Hamzah, J. (2018). Dorongan usahawan IKS dalam inovasi pembungkusan di Malaysia. Journal of Global Business and Social Entrepreneurship, 4(13), $1-15$.

McEachern, M.G., \& Warnaby, G. (2008). Exploring the relationship between consumer knowledge and purchase behaviour of value-based labels. International Journal of Consumer Studies, 32(5), 414-426.

Md Nor, N.G., Bhuiyan, A.B., Said, J., \& Alam, S.S. (2016). Innovation barriers and risks for food processing SMEs in Malaysia: A logistic regression analysis. Geografia-Malaysian Journal of Society and Space, 12(2), 167-178.

Mohd Amy Azhar, M.H., \& Safiah, R. (2017). A qualitative study on non-financial factors of employee engagement outcomes in SME business in Malaysia. International Journal of Economic Research, 14(16), 245-254.

Mohd Arif, W. (2008). Teknologi pembungkusan makanan ringan. (Paper Work Kursus Pembungkusan Makanan Ringan). Serdang, Selangor.

Mohd Hafeez Al-Amin, A.W., Mohammad, I., \& Mohd Nazri, M. (2016). Factors influencing the operational excellence of small and medium enterprise in Malaysia. International Journal of Academic Research in Business and Social Sciences, 6(12), 285-297. https://doi.org/10.6007/IJARBSS/v6-i12/2496

Mohd Hizam, H., \& Usman, Y. (2016). Special issue on economics and management studies in Malaysia the goal attainment and future direction of business among SME Entrepreneurs. Acta Universitatis Danubius, 12(3), 5-17. Retrived from https://www.researchgate.net

Noor Hidayah, A., Kean Huat, K., \& Mansor, M.F. (2018). Implementation of green new product development among SMEs: Barriers and critical success factors. MATEC Web of Conferences, 150, 6. Retrieved from https://www.matec-conferences.org

Ragayah, M.Z., \& Rahmah, I. (2004). Pemasaran dan rantaian industri skala kecil. In. Rahmah, I. (Ed.), Industri Kecil Malaysia: Isu pembiayaan, teknologi dan pemasaran (pp. 97-117). Bangi, Selangor, Penerbit UKM.

Safaie, M., Zakirah, O., \& Zulkifli, M.U. (2016). Determinants of e-learning acceptance among agricultural extension agents in Malaysia: A conceptual framework. International Review of Management and Marketing, 6(8S), 270-279.

Sayal, A., \& Banerjee, S. (2017). Factors influencing performance of SMEs: Literature review and research propositions for SMEs. Marketing Review, 17(1), 3-32.

Sazrinee, Z.A., Raja Ahmad Azmeer, R.A.E., Rahinah, I., \& Muhammad Zaffwan, I. (2014). A semantic approach in perception for packaging in the SME's food industries in Malaysia: A case study of Malaysia Food Product branding in United Kingdom. Procedia - Social and Behavioral Sciences, 115(2013), 115-130.

Sharina, S., Zaiha, Z., Mohamad, Y., Nizam, M., Nizat, M., Rozhan, A.D., \& Rohani, C.A. (2013). Khidmat nasihat teknikal MARDI bantu pembangunan PKS. Economic and Technology Management Review, 8, 153-163.

Siti Hasnah, H., Wai Leng, L., \& Wong Wai, P. (2012). The influence of food product packaging attributes in purchase decision: A study among consumers in Penang, Malaysia. Journal of 
Agribusiness Marketing, 5, 14-28. http://doi.org/10.1.1.923.5825

SME Corporation, M. (2018). Dunia yang berhubung. Malaysia, Pendigitalan PKS.

Suhaila, N., Suhaily, S., \& Muhammad Firdaus, M.S. (2014). Faktor-faktor penyumbang kepada kejayaan dan kegagalan Perusahaan Kecil dan Sederhana (PKS) Bumiputera di Malaysia. Conference on Management and Muamalah (CoMM 2014) (1). 1-5. https://doi.org/10.1007/s13398-014-0173-7.2.

Suraiya, I., Abd Hair, A., Mohd Yusof, H., Ahmad Raflis, C.O., Sarmila, M.S., Suhana, S., Zaimah, R., \& Azima, A.M. (2015). Penelitian tingkah laku inovasi firma makanan halal kecil di Malaysia: Satu analisis tentatif. Geografia-Malaysian Journal of Society and Space, 11(2), 64-76.

Suraiya, I., Ahmad Raflis, C.O., Fahruddin, M.A.B., \& Lokhman Hakim, O. (2018). Amalan pembelajaran dan kesannya terhadap pembentukan pengetahuan serta kemahiran perniagaan dalam kalangan Generasi Z. Geografia-Malaysian Journal of Society and Space, 14(01), 1528.

Suraiya, I., \& Nur Faridah, M.Z. (2012). Impact of consumer awareness and knowledge to consumer effective behavior. Asian Social Science, 8(13), 108-114.

Suwardi Afandi, A., \& Mohd Arif, W. (2014). Persepsi pengeluar snek terhadap pembungkusan dan pelabelan. Economic and Technology Management Review, 9(b), 155-162.

Suwardi Afandi, A., Mohd Yunus, S., Yaseer Suhaimi, M., \& Tapsir, S. (2016). Technology adoption decision among food manufacturers: What are the critical factors? Economic and Technology Management Review, 11(b), 75-85.

Tinne, W. (2016). Impact of packaging on consumer buying behaviour at Dhaka City. Global Disclosure of Economics and Business, 5(2), 93-100.

Vivine, T.A. (2018). Kepentingan pembungkusan produk dalam pemasaran. Retrieved from http://www.sinarharian.com.my

Wang, J., \& Shapira, P. (2012). Partnering with universities: A good choice for nanotechnology start-up firms? Small Business Economics, 38(2), 197-215.

Wells, L.E., Farley, H., \& Armstrong, G.A. (2007). The importance of packaging design for own-label food brands. International Journal of Retail \& Distribution Management, 35(9), 677-690.

Wyrwa, J., \& Barska, A. (2017). Packaging as a source of information about food products. Procedia Engineering, 182, 770-779.

Yazdanpanah, M., \& Forouzani, M. (2015). Application of the Theory of Planned Behaviour to predict Iranian students' intention to purchase organic food. Journal of Cleaner Production, 107, 342-352.

Zafir, M.M., \& Fazilah, M.H. (2017). Keusahawanan dan mengurus prestasi sumber manusia. Bangi, Selangor, Penerbit UKM.

Zainol, B., \& Kamil, M.I. (2009). Sikap, norma subjektif dan kawalan gelagat ditanggap terhadap niat gelagat kepatuhan zakat pendapatan gaji. International Journal of Management Studies, 16(1), 31-55.

Zekiri, J., \& Hasani, V.V. (2015). The role and impact of the packaging effect on consumer buying behaviour. Ecoforum, 4(1), 232-240. 